\title{
Clinical trials of Ebola vaccine must continue despite fall in number of cases
}

\author{
Anne Gulland
}

London

Clinical trials of a vaccine against Ebola virus disease being conducted in west Africa must continue even if there are not enough definitive data on the vaccine's effectiveness, a report by a panel of international experts has said. ${ }^{1}$

The panel, convened by the Wellcome Trust and the University of Minnesota's Center for Infectious Disease Research and Policy, urged the continuation of the trials despite a recent fall in the disease's incidence. It said that safety and immunogenicity data derived from the trials will be essential for determining whether to use the vaccines in future outbreaks of Ebola virus disease and for the eventual licensing of the vaccines.

The panel also urged the identification of ways to accelerate the approval of the vaccines. It said that the World Health Organization should consider creating a permanent forum to coordinate and expedite regulatory review processes.

Jeremy Farrar, director of the Wellcome Trust, which is funding the phase II/III trial of the chimp adenovirus type 3 vaccine that began in Liberia in January, said that even though the incidence of Ebola in the three worst affected countries was falling there was a risk that the current outbreak might not be brought completely under control.

"The accelerated development of candidate vaccines in collaboration between governments, industry, academia, and philanthropy is essential. We may see an end to this Ebola epidemic within the year if we continue with the current remarkable efforts, but we must not be complacent about the inevitable future epidemics of Ebola and other emerging infectious diseases," he said.
The Liberia trial aims to recruit around 30000 people, although there are doubts as to whether there will be enough volunteers. Earlier this month a Wellcome Trust funded study of a vaccine therapy, brincidofovir, was halted when the manufacturer announced it was withdrawing because of a big drop in the number of new cases. ${ }^{2}$

The panel also said that once the current epidemic was under control stockpiling vaccines for future use should be considered. Vaccines could be used during outbreaks in coordination with traditional public health measures. Routine vaccination of healthcare workers in high risk areas should also be considered, it said.

The panel called for funding commitments of at least two years to ensure that all parts of vaccine development were covered, including stockpiling doses for future outbreaks.

The latest data published by WHO on 16 February show there has been a total of 23182 cases of the disease in Sierra Leone, Liberia, and Guinea, including 9353 deaths. The number of new cases fell significantly at the beginning of this year, but there has been a slight increase over the past three weeks.

All of The BMJ's articles on the outbreak of Ebola virus disease are at thebmj.com/ebola.

1. Wellcome Trust, Center for Infectious Disease Research and Policy. Recommendations for accelerating the development of Ebola vaccines. Feb 2015. www.cidrap.umn.edu. Gulland A. Ebola drug trial is terminated after fall in number of new cases. BMJ 2015;350:h664. 